\title{
SINERGIA
}

\author{
REVISTA DO INSTITUTO DE CIÊNCIAS ECONÔMICAS, ADMINISTRATIVAS E CONTÁBEIS (ICEAC)
}

\section{O SCREENING QUE O SER HUMANO PODE SE SUJEITAR POR CRER EM VIDA APÓS A MORTE}

\author{
TIARAJÚ ALVES FREITAS \\ LÍVIO SOARES DE OLIVEIRA* \\ GIÁCOMO BALBINOTTO NETO"**
}

\section{RESUMO}

Este artigo responde, por meio da Teoria dos Jogos, especificamente screening, porque o ser humano adota uma religião e se submete a uma série de restrições durante a sua vida. A fé é considerada como parte da cesta de mercadorias de consumo dos indivíduos. Desenvolve-se a ideia de "estágio probatório" em que, no primeiro período de existência humana, as pessoas, com base em suas crenças, se tornam aptas ou não a usufruir de um prêmio após a sua morte. O seu esforço será o sinalizador para a conquista do "prêmio". Tomando o caso do Deus bíblico, este conseguiria gerar um equilíbrio separador entre as pessoas através do comportamento dessas durante sua vida na Terra. Por fim, o trabalho começa focando, especificamente, na Bíblia, percebe-se que o screenig funciona de forma generalizada, independente de religião, explicando, no contexto de um "jogo" sequencial de informação incompleta, o comportamento de cerca de oitenta e cinco por cento da população no mundo, a qual acredita em vida após a morte.

Palavras-chave: Screening; Economia da Religião.

\section{ABSTRACT}

This paper shows, through of Games Theory, specifically screening, because the humans have religious behavior, obeying one set of rules along their lives. The faith is treated as component of one bundle with materials and spirituals goods. Is developed the idea of "training period", where, in first period of the human being, the humans, in reason of your faith, reveal or not whether shall get the award after your death. Your persistence in order to obtain those award will be employed as gauge to choose who will be approved. The principals will get to generate the separating equilibrium among the people, through of behavior of same along of their lives in Earth. Finalizing, this paper aim that the screening work very well for any religion, explain in sequencial context of information assimetry the behavior of around eighty five percent of people in the world, who belief in life after death.

Keywords: Screening; Economy of Religion.

Recebido em: 13-04-2018 Aceito em: 29-08-2018

\section{INTRODUÇÃO}

É importante salientar ao leitor que, dado o enfoque deste artigo ser com base no comportamento das pessoas sobre suas crenças em relação à vida após a morte, optou-se, metodologicamente, para a contextualização com base em uma das centenas de crenças sobre o tema. Tendo em vista a Bíblia Sagrada representar uma destas crenças e ser o livro de maior tiragem no mundo, utilizou-se para esta introdução.

Ao lermos o primeiro livro Pentateuco da Bíblia Sagrada, em seu primeiro capítulo, há a apresentação da relação que Deus pretende estabelecer, por meio de um contrato, com os únicos seres racionais por ele criados no planeta terra, ou seja, homem e mulher. Deus esclarece ao casal humano que, além da racionalidade, este possui o livre-arbítrio para tomar suas decisões. Contudo, se eles quisessem gozar do apoio divino, deveriam respeitar algumas restrições.

Mesmo tendo a possibilidade e a liberdade de praticar determinadas ações que, em princípio, não seriam consideradas condenáveis sob uma ética laica, boa parte da humanidade opta por não as praticar, em decorrência da observância de uma determinada ética religiosa.

\footnotetext{
Doutor em Economia pela Universidade Federal do Rio Grande do Sul (UFRGS), Membro do Programa de Pós-Graduação em Economia Aplicada da FURG, Docente do Instituto de Ciências Econômicas, Administrativas e Contábeis (ICEAC) da Universidade Federal do Rio Grande (FURG).

"Experiência na área de Economia, com ênfase em Economia da Religião, Indicadores Sociais e Indicadores de Ciência, Tecnologia e Inovação (CT\&I).

"Graduação em Ciências Econômicas pela Universidade Federal do Rio Grande do Sul (1985), mestrado em Economia pelo Instituto de Estudos E Pesquisas Econômicas (1990) e doutorado em Economia pela Universidade de São Paulo (2000). Atualmente, é professor associado III da Universidade Federal do Rio Grande do Sul.
} 
Ao longo das eras, os seres humanos adotaram algum tipo de credo religioso que influenciou e moldou, decisivamente, o ambiente e a sociedade em que viveram, inclusive, a economia. Na Idade Média, por exemplo, quando a vida social era quase totalmente regulada pela Igreja Católica, o juro era visto como algo a ser evitado em nome de uma determinada ética cristã. As pessoas, durante a maior parte desse período, foram desestimuladas a acumular riquezas materiais, pois, conforme o pensamento anticrematístico $^{1}$ da Igreja Católica de então, poderia pôr em perigo a salvação da alma humana. A pobreza era vista como uma condição favorecedora da beatitude eterna. Em decorrência desses ensinamentos, os fiéis católicos, em sua grande maioria, se contentavam com o mínimo necessário à sobrevivência. Com isso, o impulso aquisitivo foi desincentivado e as trocas sociais praticamente regrediram para o sistema de escambo, dado o caráter autossuficiente da economia do período. A circulação de moeda reduziu-se bastante, apenas tendo readquirido um papel importante com o crescimento das cidades e das feiras, quase no final do período medieval.

Weber (2001), em seu livro A Ética Protestante e o Espírito do Capitalismo, defende a ideia de que a Reforma Protestante contribuiu decisivamente para superar os preconceitos medievais contrários à acumulação de riquezas materiais, uma das faces do que ele classifica como "tradicionalismo". Outra categoria conceitual criada por Weber, "o espírito do capitalismo", associado à ética protestante, principalmente a de corte calvinista e puritano, teria, para esse autor, influenciado de modo inequívoco o desenvolvimento econômico dos países onde se verificou a Reforma, como teria sido o caso da Holanda, Suíça e Inglaterra.

Para além desses enfoques, surge o questionamento dos motivos que conduziram e conduzem boa parte das pessoas no mundo a adotar um determinado credo religioso. Existiriam outras razões, além daquelas de cunho sociopsicológico, que levariam os indivíduos a praticar uma religião? Por que existem tantas religiões no mundo?

Este trabalho se propõe a dirimir essas perguntas, ao menos parcialmente, por meio do enfoque econômico, especificamente por meio da abordagem do comportamento individual maximizador da Teoria do Consumidor, da Teoria dos Jogos e da Economia da Informação. Mostra-se, através da Teoria do Consumidor, como a religião pode entrar nos gostos e preferências dos consumidores, gerando cestas de bens com produtos espirituais. Em temos de Teoria dos Jogos, propõe-se um jogo que os consumidores de bens espirituais se submetem através de screening ou filtro. Os indivíduos se submetem a uma espécie de contrato de dois períodos. No primeiro período, durante suas vidas, eles escolhem se submeter a um conjunto de restrições, esperando receber um prêmio no período pós-vida. O ponto é que os indivíduos que se restringem a isso não sabem em vida se receberão o prêmio pelo esforço ou não. Desta forma 0 presente artigo cria um jogo que, atualmente, pouco mais de $85 \%$ da população da Terra acredita.

$\mathrm{Na}$ literatura internacional, já existem diversos trabalhos que estudam os mais diversos efeitos da religião na sociedade. Um survey muito interessante sobre o tema é o que foi realizado por lannaccone (1998), cujo autor reuniu as mais diferentes abordagens até então publicadas sobre a área que vem sendo chamada de Economia da Religião. Segundo lannaccone (1998), a partir da obra de Adam Smith, em 1776, houve uma lacuna de dois séculos sem estudos sobre a economia e a religião, rompida por Corry Azzi e Ronald Ehrenberg a partir de 1975. Desde então, o autor identifica algumas dezenas de economistas que desenvolveram artigos sobre o tema.

O trabalho está estruturado como segue. Na segunda seção, abordam-se os pactos que a Bíblia relata que Deus teria feito com os seres humanos, empregando conceitos da Teoria dos Jogos. Após, aborda-se à luz da Teoria do Consumidor como os agentes incorporam suas crenças em relação aos seus gostos e preferências e a suas restrições orçamentárias. Entre os produtos consumidos pelos indivíduos, surgem os bens espirituais que se somam aos bens materiais. Propõe-se, na quarta seção, dois modelos para analisar o comportamento religioso das pessoas: um modelo de gerações sobrepostas, com os indivíduos decidindo como consumirão sua riqueza em um modelo de dois períodos, e outro modelo baseado nos jogos de sinalização - screening, para tentar elucidar como se processa um contrato religioso entre agente e principal, com e sem informação assimétrica ${ }^{2}$, tendo como objetivo gerar um equilíbrio separador que satisfaça ambos os lados. Por fim, apresentam-se as considerações finais.

\footnotetext{
${ }^{1}$ Segundo o pensamento aristotélico, a crematística foi definida como o conjunto de atividades econômicas com o objetivo exclusivo de acumular riquezas como um fim em si mesmo, sem ter como preocupação o fato de como essas riquezas seriam empregadas posteriormente.

${ }^{2} \mathrm{O}$ problema Agente e Principal decorre das dificuldades que podem surgir quando um principal contrata um agente para atingir um determinado conjunto de objetivos e o agente não busca atender o objetivo do principal, mas os seus próprios objetivos. Isto gera um conflito de interesses entre as partes. Esta situação surge em ambientes de informação assimétrica e incompleta entre 0 agente e 0 principal. Se considerarmos a data de assinatura do contrato entre eles e o desvio do que foi acordado ocorrendo implica na ocorrência da situação denominada de moral hazard, ou perigo moral, onde o agente muda seus objetivos para attender o que é melhor para si e não o que é melhor para o principal. Para uma pesquisa mais ampla sobre o tema ver Molho (1997).
} 


\section{O PACTO ADÂMICO}

Novamente, chama-se a atenção que o artigo se utiliza de uma das crenças existentes na história da humanidade para contextualizar este artigo. Poderia ser utilizada a crença judaica, muçulmana, xintoísta, budista, espírita, entre outras. O fato é que a religião no mundo tem como característica comum a crença de vida após a morte. É preciso ter em mente que o artigo metodologicamente utiliza uma crença em particular, mas que pretende, no momento oportuno, realizar a generalização em relação a todas as religiões, inclusive incorporando os indivíduos que não possuem religião.

É interessante notar que a literatura econômica, através de BRAMS $(1982)^{2}$, apresenta um jogo sob a luz da Teoria dos Jogos, aceca do momento em que a Bíblia relata a criação do primeiro casal humano e os objetivos de Deus para com esse casal e sua descendência. BRAMS (ibidem) teoriza que Deus teria considerado um conjunto de estratégias para se relacionar com o primeiro casal humano. Esse conjunto estaria baseado nos seguintes pressupostos:

i. Deus teria duas ações possíveis: a primeira, impor restrições $(\mathrm{IR})$ à condição humana e a segunda, a não imposição destas (ÑIR);

ii. Os seres humanos teriam como ações obedecer $(\mathrm{O})$ ou não obedecer (ÑO) às imposições.

Nesse formato, o jogo ${ }^{3}$ apresentaria quatro resultados possíveis, ou seja:

Espaço de Estratégias = $\{(I R ; O),(I R ; \tilde{N O}),(\tilde{N} I R ; O)$ e $(\tilde{N} I R ; \tilde{N} O)\}$

Esses quatro resultados são ranqueados por BRAMS (ibidem), de um a quatro, para a representação do ganho gerado em cada payoff para os jogadores, como mostra a matriz de resultados abaixo:

TABELA 1 - O jogo de imposição de restrições e (des)obediência

\begin{tabular}{clcc} 
& & \multicolumn{2}{c}{ Adão e Eva } \\
& \multicolumn{1}{c}{ Deus } & $\frac{\text { Obediência }}{(3,2)}$ & $\frac{\text { Não Obediência }}{(2,3)}$ \\
FONTE: Brams (1982) & $\underline{\text { Não Impõe Restriçãão }}$ & $(4,1)$ & $(1,4)$ \\
\cline { 2 - 3 } & & &
\end{tabular}

A ideia por trás dos resultados dos payoffs propostos é que, no caso (ÑIR;O), o ganho para Deus é o máximo possível, porque, mesmo não impondo restrição, o casal humano obedece. Já para Adão e Eva, o seu ganho é o menor possível, pois estão restringindo seus gostos e preferências. O segundo melhor resultado para Deus seria impondo restrição e o casal humano obedecendo. E os dois piores resultados

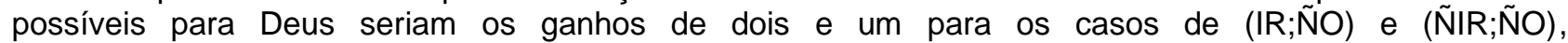
respectivamente. Do lado humano, o melhor resultado possível seria obtido se eles não obedecessem e Deus não impusesse restrição e o pior resultado seria se eles obedecessem com Deus mantendo a não imposição.

Veja que o ótimo de Paretto, em cada espaço de estratégias, é igual. Ou seja, a soma dos ganhos coletivos é a mesma para cada payoff possível. Em relação às ações extremas, o melhor resultado para Deus é (NIR;O) e para o casal humano (NIR;NO).

Pode-se notar que este jogo apresenta um equilíbrio de Nash, com o resultado da imposição de restrição por Deus e desobediência dos homens (IR;NO). Este acabou sendo o desfecho da passagem humana pelo Éden narrada no livro de Gênesis.

\subsection{Um novo pacto bíblico com a presença de screening}

O jogo apresentado na seção anterior é deveras interessante, contudo há uma questão importante que não é considerada. Adão e Eva já recebem de Deus a vida eterna ${ }^{3}$, ou seja, já possuem o prêmio máximo. Sendo assim, não há qualquer incentivo para que exerçam esforço, dadas as restrições impostas.

\footnotetext{
${ }^{2}$ Este é o artigo original de S. J. Brams que deu origem ao livro Biblical Games: Game Theory and Hebrew Bible. Mit Press: 2003.

$3 \mathrm{Um}$ jogo, com base na Teoria dos Jogos, precisa apresentar um processo de interação estratégica entre os agentes envolvidos. Existe uma dependência de um em relação a outro e vice-versa. Então basicamente um jogo precisa apresentar as regras de como é o jogo, os jogadores, as estratégias de cada jogador, a função recompensa ou payoffs para cada jogador. O jogo pode ser simultâneo em termos do espaço de estratégias de cada jogador ou sequencial. Ele também pode não ser de informação completa e perfeita. Os jogadores podem não saber todas as informações do jogo, até mesmo os payoffs. Tem-se, assim, possibilidades de assimetria de informação no jogo. Para mais detalhes ver MAS-COLELL (1995).

${ }^{3}$ Gênesis 2, 16-17: "O SENHOR Deus deu-lhe uma ordem, dizendo: Podes comer de todas as árvores do jardim. Mas da árvore do conhecimento do bem e do mal não deves comer, porque, no dia em que dela comeres, com certeza morrerás" Bíblia Sagrada (2002)
} 
Contudo, mesmo com a desobediência do primeiro casal humano, Deus resolve manter seu propósito para as próximas gerações. Desencadeia-se todo um processo ao longo do tempo e dos textos canônicos. Uma linhagem é escolhida a partir de Abraão, de sua descendência viria alguém que, tendo a mesma condição original de Adão ${ }^{4}$, estaria apto a pagar o resgate da aliança com Deus. Esta pessoa teria sido Jesus Cristo e a sua passagem pela Terra está descrita no Novo Testamento.

Como Deus mantém o propósito de uma aliança com os homens, surge um novo jogo, ou uma nova proposta de contrato. Contudo, há uma mudança fundamental. Os humanos não possuem mais a perfeição e agora terão de sinalizar esforço durante toda a sua existência na terra para conquistarem a promessa de Deus originalmente feita a Adão e Eva.

Para isso, eles terão de seguir os Dez Mandamentos ${ }^{5}$ de Moisés no período compreendido pelo Antigo Testamento, bem como realizar sacrifícios de animais, sinalizando o perdão por seus pecados, comunhão e aliança com Deus. A partir dos livros compreendidos como Novo Testamento, o mandamento máximo seria o amor e Jesus Cristo encerraria o período de sacrifícios ao fornecer a si próprio como resgate da raça humana perante Deus ${ }^{6}$.

Deus apresenta, assim, um contrato de dois períodos a partir dos descendentes de Adão e Eva. No primeiro período, os homens, durante a sua vida, deveriam respeitar as leis de Deus ou não. Veja que este ponto é semelhante ao jogo do Éden de Brams (ibidem). Porém, aqui Deus já impõe suas condições e caberá aos homens optarem por obedecer a Deus ou não. Jesus usa a metáfora do joio e do trigo que mostra esta situação em Mateus 13.24-30; 36-43:

\begin{abstract}
"Jesus apresentou-lhes outra parábola: O reino dos Céus é como alguém que semeou boa semente no seu campo. Enquanto todos dormiam, veio seu inimigo, semeou joio no meio do trigo e foi embora. Quando o trigo cresceu e as espigas começaram a se formar, apareceu também o joio. Os servos foram procurar o dono e lhe disseram: Senhor, não semeaste boa semente no teu campo? Donde veio então o joio? O dono respondeu: Foi algum inimigo que fez isso. Os servos perguntaram ao dono: Queres que vamos retirar o joio? Não! Disse ele. Pode acontecer que, ao retirar o joio, arranqueis também o trigo. Deixai crescer um e outro até a colheita. No momento da colheita, direi aos que cortam o trigo: retirai primeiro o joio e amarraio-o em feixes para ser queimado! O trigo, porém, guardai-o no meu celeiro" Bíblia Sagrada (2002 pág. 1165).
\end{abstract}

\title{
A seguir segue os versículos finais que explicam o significado da parábola:
}

"Então Jesus deixou as multidões e foi para casa. Seus discípulos aproximaram-se dele e disseram: Explica-nos a parábola do joio! Ele respondeu: Aquele que semeia a boa semente é o Filho do Homem. O campo é o mundo. A boa semente são os que pertencem ao Reino. $O$ joio são os que pertencem ao Maligno. $O$ inimigo que semeou o joio é o diabo. A colheita é o fim dos tempos. Os que cortam o trigo são os anjos. Como o joio é retirado e queimado no fogo, assim também acontecerá no fim dos tempos: o Filho do Homem enviará seus anjos e eles retirarão do seu reino toda causa de pecado e os que praticam o mal; depois, serão jogados na fornalha de fogo. Ali haverá choro e ranger de dentes. Então os justos brilharão como o sol no Reino de seu Pai. Quem tem ouvidos ouça." Bíblia Sagrada (2002 pág. 1165,1166).

Ao impor as condições e os seres humanos terem de tomar a decisão de seguir a Deus ou não, este formato estaria praticando um screening, uma espécie de jogo de sinalização dentro do arcabouço da Teoria dos Jogos. No screening bíblico, Deus oferece um contrato tal que obriga o ser humano a revelar o seu tipo, seguindo ou não as restrições impostas pelo ser Divino.

O primeiro jogo apresentado por Brams (ibidem) começou e terminou no Paraíso. O segundo jogo, aqui proposto, iniciou-se após a expulsão do primeiro casal do Éden e se desenvolveu através do período do Antigo Testamento, do Novo Testamento ${ }^{7}$, perpetuando-se e tornando-se um jogo contemporâneo.

\section{UMA PROPOSTA DE ABORDAGEM MICROECONÔMICA}

Tomando um enfoque microeconômico através da Teoria do Consumidor, sabe-se que as pessoas no mundo administram seus gostos e suas preferências através de um limitador chamado de restrição orçamentária. Pode-se configurar um vetor de bens oriundos da fé das pessoas. Este enfoque visa trazer

\footnotetext{
${ }^{4}$ Segundo a Bíblia, um ser perfeito e sem pecados, assim como Adão era antes de provar do fruto da árvore do conhecimento do bem e do mal.

${ }^{5}$ Deuteronômio 5, 6-21.

6 "Naquele tempo, Jesus ergueu os olhos ao céu e disse: "Pai, chegou a hora. Glorifica o teu Filho, para que o teu Filho te glorifique, e, porque lhe deste poder sobre todo homem, ele dê a vida eterna a todos aqueles que lhe confiaste. Ora, a vida eterna é esta: que eles conheçam a ti, o único Deus verdadeiro, e àquele que tu enviaste, Jesus Cristo. Eu te glorifiquei na terra e levei a termo a obra que me deste para fazer." João (Jo 17, 1-11a).

7 No Novo Testamento, é estabelecido por Jesus Cristo um novo pacto de Deus com os homens, chamado por Jesus de a "Nova Aliança", indicando que a Antiga Aliança, baseada na Lei Mosaica (isto é, estabelecida sob Moisés), estaria superada a partir daquele momento, segundo está descrito em Lucas 22.19,20.
} 
objetividade para este artigo no que tange ao tema religião. As pessoas utilizam, assim, parte de sua riqueza e de seu tempo para atender aos requisitos ou às restrições de sua fé.

Seguindo a ótica de que o consumidor escolhe o que é melhor para si, pode-se supor que este dispõe de dois tipos de cestas, representadas por $\left(x_{1}, x_{2}\right)$. Admitindo-se que se possa obter os preços $\left(p_{1}, p_{2}\right)$ dos bens componentes destas cestas e que o consumidor tenha um limite de renda, chamado de restrição orçamentária, tem-se:

$$
p_{1} x_{1}+p_{2} x_{2} \leq r
$$

onde:

$$
\begin{aligned}
& x_{1} \text { - são os bens religiosos (ou espirituais) } \\
& x_{2} \text { - são os bens materiais } \\
& r \quad \text { - é a riqueza do consumidor }
\end{aligned}
$$

A equação (1) representa o conjunto orçamentário do consumidor que, aliado a seus gostos e preferências, determinará os pontos de equilíbrio. As preferências devem atender aos pressupostos clássicos ${ }^{8}$ estabelecidos pela Teoria Microeconômica e são representadas por curvas de indiferença, também chamadas de funções utilidade.

Com isso, é possível classificar três tipos básicos das preferências dos consumidores quanto aos dois tipos de bens apresentados, conforme os três gráficos a seguir.

GRÁFICO 1 - Escolha ótima de consumo para um consumidor religioso

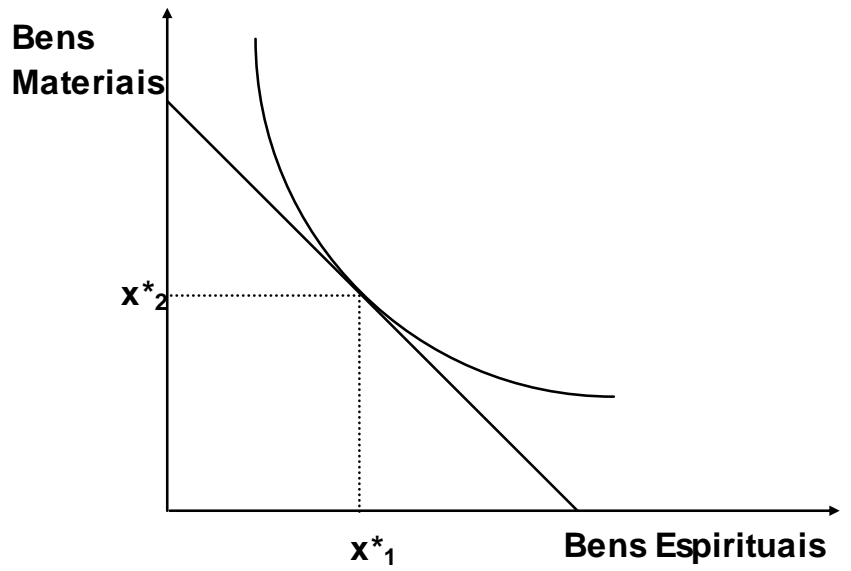

FONTE: Elaboração própria

O Gráfico 1 representa os indivíduos que possuem uma religião. Estes dedicam parte de seu tempo e riqueza em prol de sua fé, representado pelo consumo ótimo em $x_{1}^{*}$. O consumidor religioso acredita que exista alguma taxa de substituição ótima, $T M g S *$, a partir da qual possa sinalizar adequadamente a sua religiosidade ao principal - as crenças em que acredita. Essa taxa teria que igualar a relação entre os preços dos bens espirituais e dos bens materiais, $p_{X 1} / p_{X 2}$. Neste caso, temos que $T M g S^{*}=p_{X 1} / p_{X 2}$.

De forma algébrica, a solução em termos de consumo, do ponto de vista dos dois tipos de bens descritos no Gráfico 1, pode ser encontrada através de um Lagrangeano. Supõe-se uma função de utilidade Cobb-Douglas conforme abaixo:

$$
\mathrm{U}\left(\mathrm{x}_{1}, \mathrm{x}_{2}\right)=\alpha_{1} \ln \mathrm{x}_{1}+\alpha_{2} \ln \mathrm{x}_{2}
$$

Onde:

$\alpha_{1}$ representa as preferências do consumidor em relação ao bem material;

$\alpha_{2}$ representa as preferências do consumidor em relação ao bem religioso.

\footnotetext{
${ }^{8}$ a. Axiomas: Completitividade, Reflexividade e Transitividade.

b. Propriedades: Monotonicidade e Convexidade.
} 
Conforme os valores de alfa, o consumidor terá maiores preferências de um bem em relação ao outro. Isso afetará a inclinação da curva de indiferença. Supõe-se que o somatório dos alfas dê um. Assim o Lagrangeano terá a seguinte formação:

$$
L=\alpha_{1} \ln x_{1}+\alpha_{2} \ln x_{2}+\lambda\left[R-p_{1} x_{1}-p_{2} x_{2}\right]
$$

Aplicando as condições de primeira ordem, resolvendo para a demanda do bem um e do bem dois, chega-se às demandas marshallianas abaixo:

$$
\begin{aligned}
& x_{1}=\alpha_{1} R /\left(\alpha_{1}+\alpha_{2}\right) p_{1} \\
& x_{2}=\alpha_{2} R / /\left(\alpha_{1}+\alpha_{2}\right) p_{2}
\end{aligned}
$$

Tem-se, então, que os gostos e preferências, o preço de cada bem e a renda do consumidor afetam o consumo ótimo dos dois tipos de bens. Conforme será visto, hoje no mundo, cerca de $85 \%$ da população apresentam demandas de consumo que envolvam o bem dois, calculado de forma genérica na equação 4 . As demais situações, como irreligiosos e ultrareligiosos serão contempladas no gráfico 2 e no gráfico 3 .

GRÁFICO 2 - Escolha ótima de consumo para um consumidor irreligioso (ateu, agnóstico ou totalmente materialista)

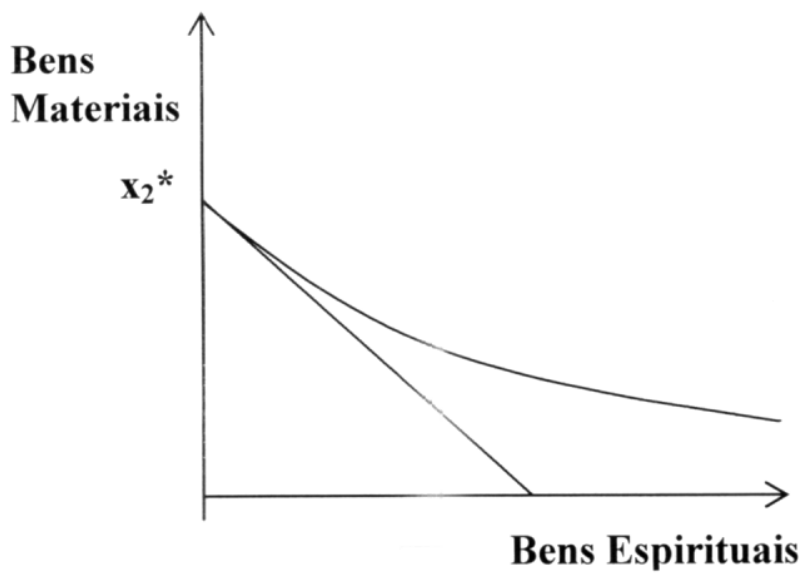

FONTE: Elaboração própria

Representamos, no gráfico acima, o comportamento de um típico indivíduo irreligioso, o que pressupõe um consumo ótimo somente de bens materiais. Esses indivíduos têm as suas preferências moldadas de tal forma que a sua taxa marginal de substituição é muito inferior à inclinação de sua linha de restrição orçamentária. Matematicamente, temos que $T M g S^{*}<p_{x 1} / p_{x 2}$, o que caracteriza o comportamento irreligioso como uma típica solução de canto, no que se refere à escolha ótima entre bens religiosos e bens materiais.

GRÁFICO 3 - Escolha ótima de consumo para um consumidor Ultrarreligioso (que se desprende de bens materiais)

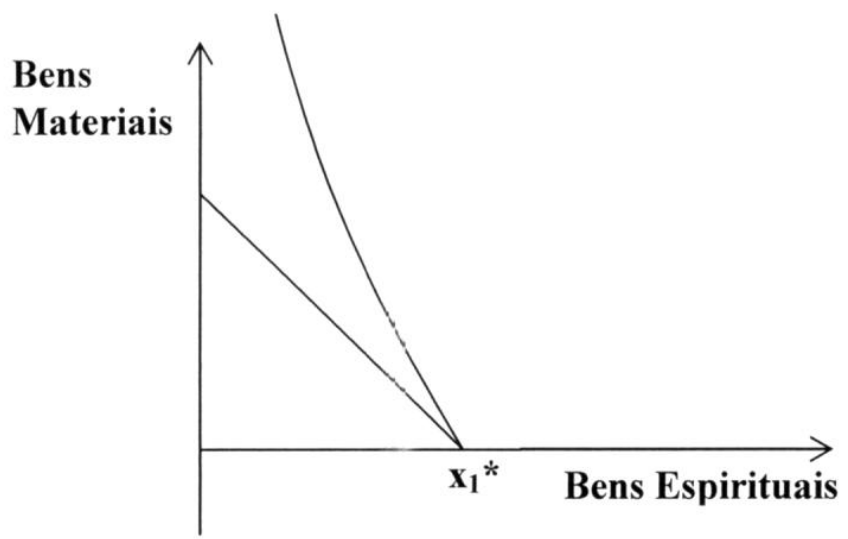

FONTE: Elaboração própria 
O Gráfico 3 representa a escolha ótima de pessoas que abdicam de suas posses e de bens materiais em prol de sua fé, que denominamos de ultrarreligiosos, o que gera um consumo ótimo somente de bens religiosos. Nesta categoria, podem-se incluir pessoas como o Buda Siddharta Gautama, São Francisco de Assis, Gandhi, Madre Teresa de Calcutá, dentre outros. Inversamente ao anterior, esse caso reflete uma escolha ótima em que a taxa marginal de substituição dos indivíduos é muito superior à inclinação de sua linha de restrição orçamentária, isto é, $T M g S^{*}>p_{x 1} / p_{x 2}$.

O caso representado pelo Gráfico 1 pode ser classificado como um comportamento tipicamente geral, que abrange a maioria da população do mundo. Essa conclusão pode ser deduzida da Tabela 1 da seção seguinte, a partir da qual também concluiremos que o caso representado pelo Gráfico 2, que retrata o comportamento de indivíduos irreligiosos, respectivamente, é minoritário. O caso que o Gráfico 3 representa, de um indivíduo que abre mão, voluntariamente, do consumo de bens materiais, apesar de poder adquiri-los, é muito mais restritivo ainda, pois apenas poucos indivíduos tomam a decisão extrema de dedicar-se inteiramente à religião. Partindo do caso padrão representado no Gráfico 1, conforme variem no tempo as preferências intertemporais dos indivíduos em relação à escolha dos bens materiais/religiosos, as suas respectivas taxas marginais de substituição tornam-se maiores ou menores do que sua linha de restrição orçamentária. À medida que essa desigualdade se acentua, o comportamento dos indivíduos pode se aproximar de um dos dois casos extremos representados pelas soluções de canto dos Gráficos 2 e 3 , isto é, o puro materialismo, $T M g S^{*}<p_{x 1} / p_{x 2}$, ou a devoção religiosa extremada, $T M g S^{*}>p_{x 1} / p_{x 2}$.

Tem-se, assim, sob a ótica da Teoria do Consumidor, a forma como os consumidores se comportam em relação a sua espiritualidade ou religiosidade. $O$ arcabouço que propomos aqui não é novo, e, sim, a determinação do espaço de atuação dos três tipos de consumidores, que representam o comportamento da população deste planeta em relação ao modo de alocação do seu consumo, em que uma boa parte dessa população consome bens derivados da subjetividade da fé individual, que classificamos como sendo bens religiosos ou espirituais.

\subsection{Generalizando para todas as religiões}

Um passo adicional que este trabalho dá, a partir de agora, é o de não focar o comportamento do ser humano quanto ao que poderia acontecer após a sua morte, tendo como única fonte os livros canônicos da Bíblia.

Existem, no mundo atualmente, mais de sete bilhões de pessoas. Segundo estudos realizados pela Universidade de Oxford através da World Christian Encyclopedia (ver Tabela 1 a seguir), apenas quinze por cento da população mundial não possui religião ou é atéia. $O$ restante está distribuído entre as mais diversas religiões existentes, como, por exemplo, muçulmanos, hinduístas, budistas, espíritas, confucionistas, xintoístas, entre outros. Nota-se que os muçulmanos, em conjunto com os cristãos, representam em torno de metade da população da Terra.

TABELA 1 - Classificação da população no mundo segundo suas crenças religiosas

\begin{tabular}{c|c}
\hline RELIGIÃO & TOTAL \\
\hline Cristãos & $33,09 \%$ \\
\hline Muçulmanos & $20,36 \%$ \\
\hline Hinduístas & $13,48 \%$ \\
\hline Sem religião & $11,91 \%$ \\
\hline Beligiões populares Chinesas & $6,27 \%$ \\
\hline Budistas & $5,87 \%$ \\
\hline Atno-religiosos & $3,97 \%$ \\
\hline Ateus & $2,35 \%$ \\
\hline Seoreligiosos & $1,68 \%$ \\
\hline Sikhs & $0,39 \%$ \\
\hline Judeus & $0,23 \%$ \\
\hline Baháritas & $0,20 \%$ \\
\hline Confucionistas & $0,12 \%$ \\
\hline Jainistas & $0,10 \%$ \\
\hline Xintoístas & $0,07 \%$ \\
\hline Taoístas & $0,04 \%$ \\
\hline Zoroastristas & $0,04 \%$ \\
\hline Outras religiões & $0,04 \%$ \\
\hline Dupla filiação & $0,00 \%$ \\
\hline TOTAL DA POPULAÇÃO & $-0,23 \%{ }^{*}$ \\
\hline
\end{tabular}

NOTA: * O sinal negativo significa que, para não haver dupla contagem, são descontados do total da população os indivíduos que possuem mais de uma religião.

FONTE: Adaptado pelos autores, com base na World Christian Encyclopedia, em http://worldchristiandatabase.org/ 
Observando a Tabela 1, pode se questionar por que surgiram e surgem tantas religiões no mundo. Hobbes (2003), no Leviatã, argumenta que o motivo fundamental para esse fato foi a dificuldade ou incapacidade de boa parte da humanidade para explicar fenômenos cujas causas the são desconhecidas. Hobbes (Ibidem) aponta o papel que as religiões tiveram ao longo dos tempos, em diferentes lugares, como instrumentos usados pelas elites governantes para obter a coesão e a disciplina da sociedade, o que foi fundamental, por exemplo, para a expansão das atividades econômicas. É um ponto pacífico que as religiões, em suas mais variadas formas e ritos, em muitos casos, foram usadas, desde tempos imemoriais, como meio de conferir prestígio às classes que se autointitulavam mediadoras entre um mundo espiritual e a humanidade. Isso foi possível, por exemplo, pela divinização dos Faraós do Egito Antigo, dos soberanos da Antiga Mesopotâmia e dos Césares Romanos, além da divinização do próprio Estado. O surgimento da religião está associado ao próprio surgimento das civilizações antigas do Crescente Fértil, entre elas, a egípcia, suméria, assíria, caldeia, babilônia e hebraica, com a criação do Estado-Nação e das classes sociais. Outros exemplos bem conhecidos foram o surgimento e a expansão do Império Árabe após a fundação do Islamismo por Maomé, além do Sacro Império Romano Germânico sob o rei Carlos Magno. Como neste último caso, o poder civil na Europa, durante o período medieval, influenciou e foi influenciado pela ação direta da Igreja Católica em Roma.

Por outro lado, cabe perguntar por que as pessoas se interessam em praticar uma religião. Em essência, não acreditam em viver somente o período de sua vida humana. Segundo Hobbes (ibidem), isso se explica pelo medo, insegurança e ansiedade humanas em relação ao que poderia acontecer no futuro e pela tentativa de uma parte da humanidade de controlar fatores cujos determinantes the são desconhecidos. Nesse sentido, a ignorância humana, representada pela escassez ou falta de informação, que é um problema típico de assimetria informacional, para conseguir explicar essas causas, foi um ingrediente fundamental para a existência das religiões.

As pessoas consideram que as suas decisões influenciariam pelo menos dois períodos de sua existência. O ser humano estaria participando de uma espécie de "estágio probatório". Seria oferecido um contrato de dois estágios (períodos) onde, durante a sua estada na Terra (primeiro estágio) e de acordo com seu desempenho, estaria apto ou não a conquistar um prêmio de acordo com suas crenças, como, por exemplo, a conquista de um novo Paraíso (segundo estágio), como o retratado no livro bíblico de Gênesis, para o caso das religiões que utilizam esta literatura.

Vale ressaltar que o prêmio existente oferecido pelas religiões para as pessoas no segundo estágio tem uma característica diferenciada, quando comparado à Teoria dos Torneios ${ }^{4}$, desenvolvida pela literatura econômica desde o final do século vinte. A Bíblia não coloca o prêmio pós-estágio probatório como uma competição entre colegas. É uma corrida que não importa se você é o primeiro colocado ou o último, mas que você chegue ao final da corrida ${ }^{9}$. É como se tivesse de obter um número de pontos mínimo para passar para a próxima fase. O problema é que não se sabe se a pontuação foi atingida ou não.

Para o principal, seria gerado, no primeiro período, um equilíbrio separador em que as pessoas se distinguiriam por adotarem ou não um comportamento que resultasse no prêmio no próximo período. Com esta informação, o principal premiaria aqueles que passaram no "estágio probatório", eliminando o chamado "joio" do "trigo".

\section{MODELOS PROPOSTOS}

\subsection{Um modelo de gerações sobrepostas para o comportamento do agente}

A primeira abordagem a ser usada teve como inspiração o modelo de gerações sobrepostas proposto por Diamond (1965). Ao longo do tempo, a pessoas nascem e morrem. Contudo, uma forma de simplificar esse ponto é trabalharmos com o conceito de tempo discreto. As variáveis a serem utilizadas serão distribuídas no tempo $t=0,1,2, \ldots$ Para nossa análise, se $o$ indivíduo está vivendo no período $t$, o período $\mathrm{t}+1$ representaria o seu período pós-vida. Cada indivíduo poderá consumir bens espirituais que representem a sua fé, de cujo consumo derivaria uma determinada utilidade em relação ao período pós-vida ${ }^{10}$. Isso

\footnotetext{
${ }^{4}$ A Teoria dos Torneios de promoção - Tournaments - trabalha com a hipótese que existe um incentivo para que os indivíduos envidem maiores níveis de esforço no trabalho, pois esperam ser reconhecidos através das remunerações e estarem aptos a obter ou poder disputar novas promoções nas instituições a que pertencem (LAZEAR, 1998). Ao se utilizar avaliação de desempenho em um grupo pode-se distribuir o sistema de recompensas. Tem-se, assim, uma situação de torneio de promoção, ou seja, uma competição para classificar os indivíduos de acordo com o nível de produtividade.

${ }^{5}$ É o que é ilustrado pela Parábola dos trabalhadores na vinha de Mateus 20.1-18, os quais, independentemente do período do dia em que foram contratados para trabalhar, receberam o mesmo salário de um denário. É o que também ficou caracterizado no caso do ladrão arrependido na cruz, ao qual Jesus garantiu que o prêmio do Paraíso lhe seria concedido, com as seguintes palavras "hoje mesmo estarás comigo no Paraíso", conforme está descrito em Lucas 23.39-43. Essas passagens bíblicas trazem implícito o ensinamento de que não é a extensão do tempo, menor ou maior, que as pessoas passaram numa religião que lhes garantirá uma recompensa espiritual, mas, sim, a fé (arrependimento) e a obediência efetivamente demonstradas em atos e palavras.

${ }_{10}$ Uma amostra deste conjunto de prováveis bens seria: dedicação do tempo em orações, ajuda ao próximo, respeito aos dez
} 
resultaria em uma riqueza futura a ser gozada no segundo período. Vale lembrar que ele não sabe se este segundo período existe. Em $\mathrm{C}_{1 \mathrm{t}}$ e $\mathrm{C}_{1 \mathrm{t}+1}$, o consumo no período $\mathrm{t}$ da pessoa em vida e da pessoa pós-vida, respectivamente. A função utilidade $\left(\cup_{t}\right)$ apresentada aqui é uma derivação da tradicional função utilidade com aversão ao risco relativo constante (constant-relative-risk-aversion), sendo dada por:

$$
U_{t}=(1-\rho) \frac{C_{1 t}^{1-\theta}}{1-\theta}+\rho \frac{C_{1, t+1}^{1-\theta}}{1-\theta}
$$

onde:

$U_{t}=$ utilidade dos indivíduos no período t.

$\theta$ = parâmetro que determina quanto o consumo dos indivíduos varia intertemporalmente;

$\rho=$ parâmetro que determina a taxa de preferência intertemporal dos indivíduos;

Consideramos que $0 \leq \rho<1$ e $0<\theta \neq 1$.

Se $\rho \rightarrow 0$, os indivíduos atribuem maior peso no consumo do primeiro período em relação ao segundo período. Por outro lado, se $\rho \rightarrow 1$, ocorre o inverso. A situação em que $\rho=0$ caracteriza os indivíduos que não acreditam na existência do segundo período.

Um ponto chave que se abre aqui é o valor de $\rho$. Ele tem de ser tal que não permita dúvidas sobre o esforço do agente para o principal. $O$ indivíduo não sabe qual é o seu valor, mas tem indicações do que deve ser feito para que o principal o escolha. Note que o valor de $\rho$ cria um refinamento adicional para os indivíduos que foram considerados "trigo" pelo modelo.

Gostaríamos de fazer mais duas considerações em relação ao $\rho$. Primeiro, o $\rho$ poderá classificar, por exemplo, tanto aquelas pessoas que combinam bens materiais e bens espirituais simultaneamente, como no Gráfico 1, como as pessoas que abrem mão de todos os bens materiais como representado na Gráfico 3.

O segundo, a oportunidade do principal criar um novo equilíbrio separador, classificando vários tipos de $\rho$. Uma classe possível seria aquela que, literalmente, consumiu a compra de uma vaga no céu em posição privilegiada. Este caso, entre outros, também poderia ser considerado "joio", através de um processo de refinamento por parte do principal.

Ao longo do tempo, as pessoas têm exercido os mais diferentes níveis de esforço quanto à sua fé em relação ao "pós-vida", dada a sua função-objetivo. Se as suas crenças são de que não há nada após sua morte, então a solução é trivial. Agora, se ao contrário, Ihes importa o "pós-vida", então elas exercerão um nível de esforço que as tornem aptas a serem escolhidas como"trigo" pelo principal.

\subsection{Um modelo de screening religioso}

Tendo por base os modelos desenvolvidos por Spence (1973) e Stadler (1997), em que a variável educação é analisada como meio da sinalização dos trabalhadores em relação aos empregadores, no que se refere ao seu grau de produtividade, iremos considerar um modelo adaptado aos propósitos deste artigo, cuja variável de sinalização é o grau de religiosidade dos indivíduos, como, por exemplo, a sua fé e a obediência aos preceitos estabelecidos por determinada religião.

Consideraremos, inicialmente, um "mercado" da fé ou "mercado" religioso, querendo dizer com isso que é um espaço intertemporal de livre competição entre as diferentes religiões que disputam a fé das pessoas. Cada religião ou crença religiosa com seus diferentes credos, preceitos e normas tem a sua divindade, que chamaremos de principal ou de principais, que tentam estabelecer um contrato religioso com as pessoas, por meio dos que são considerados representantes da divindade: os líderes clericais ou classes sacerdotais das diversas religiões. Para simplificar nossa exposição, sempre que nos referirmos à religião ou religiões, estaremos identificando estas com seu principal ou principais.

Às pessoas que são disputadas pelas religiões ou que aceitam ou não estabelecer um contrato religioso com o principal, chamaremos de agentes. Pode acontecer comumente que diferentes religiões tenham a mesma divindade ou o mesmo principal, como no caso do judaísmo e do cristianismo. Semelhantemente, pode acontecer que os agentes se filiem a mais de uma religião - ver dupla filiação na Tabela 1. Isso não quer dizer, necessariamente, que tenham contratos com mais de um principal, pois, como dissemos, um mesmo principal pode ser o mesmo em várias religiões. As diversas religiões existentes poderiam ser comparadas a empresas religiosas que estão competindo pela filiação das pessoas a seus dogmas. 
Quando dizemos livre competição religiosa, neste caso, não estamos afirmando que exista concorrência perfeita entre as diversas religiões existentes, pelo contrário. Esse tipicamente é um mercado de concorrência imperfeita. É bem sabido que sempre existiram religiões ao longo da história humana que, por serem consideradas oficiais, foram favorecidas em detrimento das outras por contarem com o apoio do Estado. É o caso, por exemplo, dentre outros, do Atonismo durante o reinado do Faraó Amenotep IV ou Akinaton (1375-1358 a.C.) no Egito Antigo, o culto a Júpiter em Roma ou o catolicismo romano nas nações europeias durante a Idade Média ou no Império Romano a partir de sua ascensão como religião oficial do Estado por Constantino. Evidentemente, o apoio estatal, nesses e em tantos outros casos, permitiu que essas religiões fossem beneficiadas, atraindo um grande número de adeptos, em decorrência do status social que os praticantes adquiriam, deixando, consequentemente, as demais religiões concorrentes em desvantagem. No entanto, o apoio oficial não quer dizer que tais religiões mantiveram ou manterão essa vantagem, como ocorreu com o Atonismo, que, após a morte do seu fundador, Akinaton, deixou de existir. É interessante notar que nesse aspecto as religiões são também semelhantes a empresas, porque, como estas, podem surgir, expandir-se, estabilizar-se, definhar e, até mesmo, desaparecer.

Para atender aos objetivos de nosso trabalho, adotaremos aqui o conceito de "produtividade religiosa", o que pode ser avaliado pelo grau de fé e obediência do agente aos preceitos estabelecidos no contrato religioso com o principal. Para efeito de simplificação, assumiremos, em nosso modelo, que existem dois tipos de agentes no mercado religioso: agentes com boa produtividade religiosa, que classificaremos como sendo do tipo $\mathrm{B}$, e agentes com má produtividade religiosa, que classificaremos como sendo do tipo $\mathrm{M}^{10}$. Aos primeiros, atribuiremos uma produtividade igual a 2 , e aos últimos, uma produtividade igual a 0 .

Ao estabelecer um contrato com um agente, o principal promete a este um prêmio ou recompensa, que pode ser, por exemplo, a imortalidade ou vida eterna. Esta é a recompensa espiritual, que chamaremos de $w$. O principal tem interesse em que os agentes cumpram os termos do contrato religioso. O seu lucro será a satisfação oriunda da obediência e da fé do maior número possível de agentes. Esse lucro será 2 ou 0 , de acordo com o perfil da produtividade religiosa dos agentes ${ }^{12}$. Presume-se que o principal das religiões conheça, a priori, esse perfil, premiando os agentes com boa produtividade espiritual, com uma recompensa igual a 2 , não concedendo nenhum prêmio aos agentes com má produtividade ${ }^{13}$.

Adota-se a premissa de que todos os agentes têm a possibilidade de escolher (ou não) o tipo de contrato religioso que mais lhes agradam. Isto é, todos os agentes podem sinalizar (ou não) de livre e espontânea vontade, por meio de sua fé, que estão aptos a receber um prêmio. A prática dessa religião terá um custo para o agente, que será maior ou menor, dependendo de seu tipo. Esse custo está associado ao tempo dedicado à prática religiosa pelo agente e será indicado por $y$. Se o agente for do tipo $\mathrm{B}, \mathrm{o}$ custo da prática religiosa para o mesmo será de $y / 2$. Se o agente for do tipo $\mathrm{M}$, o custo dessa prática religiosa será de $y$. Em nosso modelo, para fins de simplificação, consideramos que o tempo $t$ dedicado à prática religiosa tem efeito sobre a produtividade religiosa do agente.

No equilíbrio do jogo de sinalização, adotaremos o pressuposto de que as religiões têm um critério padrão de classificação quanto à produtividade religiosa de seus agentes, que é a avaliação do grau de fé e de obediência destes aos preceitos religiosos. Esse critério será endossado ou não de acordo com o comportamento dos agentes e está baseado num nível considerado aceitável em termos de prática religiosa, que chamaremos de $y^{*}$. Suporemos que as religiões avaliam que um candidato ao prêmio

\footnotetext{
${ }^{11}$ Agentes com boa produtividade religiosa seriam, por exemplo, os devotos religiosos ou que têm fé. Os agentes de má produtividade religiosa seriam, em princípio, por exemplo, os adeptos não religiosos, os ateus, os agnósticos e os materialistas em geral. Isso não quer dizer que excluímos dessa análise, para efeito do recebimento da recompensa pelo agente, as exceções a essa distinção geral que fizemos. Um agente pode se dizer religioso, mas apresentar um comportamento não condizente com a fé que diz professar. Neste caso, estaria sinalizando ao principal o contrário de sua alegada condição religiosa, isto é, que seria um agente do tipo $\mathrm{M}$. Isso seria semelhante ao caso de um trabalhador que comprou um diploma universitário para sinalizar a um empregador que seria de alta produtividade, sendo antes de baixa produtividade. Em contrapartida, um agente que professasse o ateísmo ou o materialismo e, concomitantemente, sinalizasse por seu comportamento ao principal que seria do tipo $\mathrm{B}$, seria recompensado pelo principal, não importando se possuía filiação religiosa ou não. Poderíamos fazer uma analogia desse caso com o de um trabalhador que não tem título universitário, mas que tem alta produtividade, por ser um autodidata aplicado, por exemplo. O que importa, em nossa análise, é que somente os agentes que forem classificados pelo principal como sendo do tipo B é que farão jus ao prêmio espiritual, ficando os agentes classificados como sendo do tipo $\mathrm{M}$, excluídos do mesmo, independemente se os agentes de ambos os tipos pertencem ou não a uma religião. Assim, é possível que alguns agentes que não tenham estabelecido qualquer contrato religioso possam ser considerados aprovados pelo principal para receberem o prêmio espiritual. No entanto, o principal não informa esta possibilidade aos agentes, se assim o fizesse, estaria desestimulando a prática religiosa, o que seria um contrassenso do seu ponto de vista.

${ }^{12}$ Fizemos a suposição de que a recompensa espiritual não representa um custo do ponto de vista do principal.

${ }^{13}$ Adotamos a premissa de que os agentes com má produtividade religiosa não recebem nenhum prêmio, o que nos parece bastante razoável. Caso as religiões sinalizassem com um prêmio espiritual para os agentes com má produtividade religiosa, estariam, com esse sinal, desestimulando a própria prática religiosa, desautorizando o esforço dos agentes classificados como sendo do tipo $B$, o que seria, no mínimo, um absurdo. Com isso, a justificativa principal em que se apoiam as religiões para existirem como tais desapareceria.
} 
espiritual será do tipo $\mathrm{B}$ se $\mathrm{o}$ seu grau de prática religiosa satisfizer a condição de que $y \geq y^{*}$. Em contrapartida, o candidato será considerado do tipo $\mathrm{M}$ se for enquadrado na condição oposta, isto é, $y \leq y^{*}$. A partir dessas avaliações, as religiões irão ofertar aos agentes uma recompensa espiritual de $w=2$ se $y \geq y^{*}$. Por outro lado, se o agente for classificado na condição oposta, ou seja, $y \leq y *$, não receberá nenhum prêmio espiritual, isto é, neste caso $w=0$.

Com base nas ofertas espirituais feitas pelas diversas religiões, os agentes irão fazer uma escolha em relação a essas ofertas, adotando ou não uma determinada prática religiosa. Para isso, irão escolher que nível de prática religiosa satisfaz os seus objetivos ou expectativas presentes e futuras, dentre dois níveis que, para efeito de simplificação, consideraremos como possíveis, isto é, $y=y^{*}$ ou $y=0$. Formalmente, $y \in\left(0, y^{*}\right)$. Os critérios estabelecidos pelas religiões relativamente à sinalização por parte dos agentes serão endossados na prática se os agentes do tipo B escolherem $y=y^{*}$ e os agentes do tipo $M$ escolherem $y=0$. Formalmente, temos um padrão de escolhas feitas pelos agentes, quer sejam do tipo $B$ ou do tipo $M$, que obedece às seguintes condições

$$
\text { Escolha de } B \Rightarrow 0-0 \leq 2-\frac{y^{*}}{2}
$$

Escolha de $M \Rightarrow 2-y^{*} \leq 0-0$

O que significa que $y^{*} \in[2,4]$, isto é, o grau de prática religiosa dos agentes que está contido nesse intervalo é considerado ótimo pelo principal, o que caracteriza um nível de sinalização de equilíbrio múltiplo. Se o principal avalia que um agente tem boa produtividade religiosa, isto é, como tendo fé suficiente, este será classificado como sendo do tipo $B$, já que, teoricamente, apenas agentes desse tipo teriam de fato incentivo para a prática religiosa. Em contrapartida, o agente de má produtividade religiosa será classificado como sendo do tipo $\mathrm{M}$ se o custo do mesmo para a prática religiosa for muito alto. Considerando que os agentes queiram sinalizar ao principal que são do tipo $B$ e, concomitantemente, queiram minimizar seus custos, optarão por escolher o menor custo, isto é, $y^{*}=2$, que será chamado de equilíbrio separador com custo mínimo.

A probabilidade de que o agente do tipo $\mathrm{B}$ conquiste o prêmio espiritual é $p^{B}$ e a probabilidade de que o agente do tipo $\mathrm{M}$ conquiste o prêmio é zero, isto é, $p^{M}=0$. A avaliação do principal relativamente ao resultado do esforço dos agentes é $\Pi_{S}$ ou $\Pi_{F}$, o subscrito $S$ significa sucesso e o subscrito $F$ indica insucesso. Neste nosso modelo adaptado, pressupomos que exista pelo menos um agente que possa ser classificado como sendo do tipo B, para que possamos caracterizar a existência de um equilíbrio separador. Consideramos, também, que existe informação assimétrica em nosso modelo, admitindo apenas que o principal tem absoluta certeza sobre quem de fato receberá o prêmio espiritual. Com isso, queremos dizer que, embora os agentes do tipo B possam sinalizar com o máximo nível de produtividade religiosa, isto é, $y^{*}=4$, apenas o principal tem a informação segura se foram considerados aprovados para receber 0 prêmio. Caso houvesse informação simétrica com os agentes, tanto do tipo $B$ como do tipo $M$, conhecendo a priori se os seus esforços lhes valeriam o prêmio espiritual, as suas utilidades e seus prêmios seriam

$$
\begin{aligned}
& U^{B^{*}}=u\left[p^{B} \Pi_{s}+\left(1-p^{B}\right) \Pi_{F}\right] \\
& U^{M^{*}}=u\left[p^{M} \Pi_{S}+\left(1-p^{M}\right) \Pi_{F}\right] \\
& w^{B^{*}}=p^{B} \Pi_{s}+\left(1-p^{B}\right) \Pi_{F} \\
& w^{M^{*}}=p^{M} \Pi_{s}+\left(1-p^{M}\right) \Pi_{F}
\end{aligned}
$$

Neste caso, se as pessoas tivessem a informação certa da existência de um prêmio espiritual futuro, independentemente do seu tipo, sinalizariam ao principal com a religiosidade. Isso quer dizer que, na prática, não haveria estímulo ou incentivo para alguém professar o ateísmo, o agnosticismo, o materialismo ou a irreligião de um modo geral. Haveria um grande incentivo à prática religiosa, em maior ou menor grau, 
já que, tendo a certeza de que somente possuindo algum grau de religiosidade poderiam receber um prêmio espiritual, as pessoas procurariam se filiar a alguma religião, admitindo a premissa de que apenas por esse meio receberiam esse prêmio. Assim, $w^{B^{*}} e w^{M^{*}}$ designariam os prêmios espirituais para os agentes de ambos os tipos, tanto os de alta como os de má produtividade religiosa, os quais estariam sinalizando com seu esforço o seu grau de mérito para a obtenção do prêmio. Aqui esse esforço nem mesmo deveria ser caracterizado como fé religiosa, já que todos teriam a informação segura da existência do prêmio ${ }^{14}$.

Como não existe a certeza concreta de que tal prêmio exista de fato, isso resulta em problemas de assimetria informacional. Sem essa certeza, muitas pessoas consideram dispensável a prática religiosa e optam por não se filiar a nenhuma religião, declarando-se irreligiosas, atéias, agnósticas ou materialistas. Somente a fé, definida como uma crença em algo não visto, é que permite justificar todo o esforço que os agentes de boa produtividade religiosa fazem para ser considerados aptos a receberem um prêmio espiritual. Como nem todos têm essa fé, isso explica porque muitos agentes optam por não alocar o seu tempo em práticas religiosas. Ainda é importante considerar que mesmo os agentes envolvidos nessas práticas podem não estar seguros a respeito da obtenção do prêmio, isto é, de que terão ou não sucesso nessa conquista.

O nosso modelo considera que existe assimetria informacional, isto é, os agentes não têm certeza em relação ao sucesso de seu esforço religioso na obtenção do prêmio ou mesmo da própria existência desse prêmio. Neste caso, o modelo com informação assimétrica apresenta as seguintes utilidades esperadas e os seguintes prêmios em relação aos dois tipos de agentes

$$
\begin{aligned}
& E\left[U^{B}\right]=p^{B} u\left(w_{s}^{B}\right)+\left(1-p^{B}\right) u\left(w_{F}^{B}\right)<U^{B^{*}} \\
& w^{B^{*}} \in\left\{w_{s}^{B}, w_{F}^{B}\right\} \\
& U^{M}=0 \\
& w^{M}=0
\end{aligned}
$$

A primeira equação de (5) significa que a utilidade esperada do agente do tipo B em relação ao prêmio espiritual com informação assimétrica é inferior à utilidade esperada que obteria caso não existisse esse problema. É simples entender por que isso ocorre. Com informação simétrica, é relativamente fácil para o agente do tipo B sinalizar esforço religioso, já que o mesmo possui certeza absoluta de que obterá o prêmio. Sem essa certeza, o agente do tipo $B$ precisa superar quaisquer dúvidas que the ocorram sobre 0 sucesso ou insucesso futuro de seu esforço atual ${ }^{15}$.

A segunda equação de (5) indica que o contrato religioso ótimo que o principal oferece ao agente do tipo B está condicionado ao desempenho deste em termos de esforço religioso, isto é, o valor da recompensa a ser recebida pelo agente do tipo B será relacionado a ter sido seu esforço considerado bemsucedido ou não.

A terceira equação significa que os agentes do tipo $M$ não derivam nenhuma utilidade da alocação do seu tempo em esforços religiosos, já que não acreditam num prêmio espiritual. A última equação significa que, considerando que esse prêmio venha a existir, os agentes do tipo $M$ não o receberão, já que não sinalizaram esforço para o principal.

No nosso modelo, assumimos a premissa de que o principal conhece o tipo do agente. Outra premissa necessária é que o agente deve escolher o tempo $t$ que deve alocar para a prática religiosa, que é observado pelo principal, entre dois valores possíveis: $t=0$ ou $t=t^{\prime}$.

\footnotetext{
${ }^{14}$ Poderia ser questionado, se a certeza do prêmio existisse, todos os agentes não iriam exercer o esforço religioso máximo, como no caso do nível de produtividade religiosa de nosso modelo em que $y^{*}=4$. Mas isso seria semelhante a perguntar por que todos os trabalhadores não têm uma alta escolaridade, sinalizando que estão aptos a receber altos salários; o que não faz sentido, já que, neste caso, se sabe que a aquisição de uma alta escolaridade está associada a fatores tais como custos de oportunidade, em que nem todos os trabalhadores estão dispostos ou aptos a incorrer a habilidades naturais ou a questões de preferência. De forma idêntica, ainda que houvesse certeza do prêmio espiritual, nem todos os agentes estariam dispostos a restringir suas escolhas atuais, optando por consumir bens espirituais em vez de bens materiais. Neste caso, tais agentes, mesmo com a certeza do prêmio espiritual para os que se esforçam por meio da obediência religiosa, em decorrência desse custo, iriam preferir um carpe diem de prazeres do presente a uma beatitude futura. De acordo com o nosso modelo de gerações sobrepostas, isso equivale a dizer que a sua taxa de preferência intertemporal $\rho$ lhes direciona a investir no consumo do primeiro período em detrimento do consumo no segundo período.

${ }^{15} \mathrm{O}$ agente do tipo $\mathrm{B}$ não sabe a priori se a sua avaliação final pelo principal será condizente com sua expectativa de receber o prêmio futuro. Pode acontecer que o agente do tipo B, duvidando da existência do prêmio futuro ou se o receberá ou não, apesar do seu esforço religioso, considere este como sendo muito penoso relativamente ao que seria se tivesse a certeza do prêmio. Consequentemente, no caso de assimetria informacional, o custo de sua prática religiosa irá aumentar e sua utilidade esperada do prêmio diminuir, já que envolve uma condição de incerteza, relativamente à condição oposta, em que houvesse informação simétrica.
} 
A prática religiosa, como tem um custo, está associada a uma desutilidade, que será de $v^{B}(t)$ quando o agente for do tipo $\mathrm{B}$ e de $v^{M}(t)$ se o agente for do tipo $\mathrm{M}$, assumindo-se que $v^{B}\left(t^{\prime}\right)>v^{B}(0)$ e $v^{M}\left(t^{\prime}\right)>v^{M}(0)$. Para efeito de simplificação, faremos $v^{B}(0)=v^{M}(0)=0 \quad e \quad v^{B} \equiv v^{B}\left(t^{\prime}\right), v^{M} \equiv v^{M}\left(t^{\prime}\right)$.

Para a prática religiosa, o agente do tipo $\mathrm{B}$ escolhe $t=t^{\prime}$ e o agente do tipo $\mathrm{M}$ escolhe $t=0$. Quando o principal observa o sinal $t^{\prime}$, ele conclui que tal sinal só pode ser enviado por um agente do tipo $\mathrm{B}$, com probabilidade igual a $q\left(t^{\prime}\right)=1$, considerando que esse sinal não pode ser enviado por um indivíduo do tipo M. Sempre que verificar o sinal $t^{\prime}$, o principal terá certeza de que quem o enviou foi um agente do tipo B. Por outro lado, se o principal observa o sinal $t=0$, ele conclui que a probabilidade de que esse sinal esteja associado a um agente do tipo B é $q(0)=0$. Dessa forma, fica caracterizado aqui um equilíbrio separador em relação ao sinal enviado pelos dois tipos de agentes. Nesse tipo de equilíbrio, o agente do tipo B não tem interesse em se comportar como se fosse do tipo $\mathrm{M}$, o mesmo raciocínio valendo para o caso oposto.

\section{CONSIDERAÇÕES FINAIS}

Ao se estudar a narração bíblica, nota-se que Deus ofereceu ao primeiro casal humano um contrato em que disponibilizava o Paraíso e em troca exigia obediência deste casal às restrições impostas. Contudo, este contrato já oferecia o prêmio sem a exigência de esforço, o que gerou um equilíbrio de Nash de não obediência por parte do casal, resultando nas consequências relatadas pelo texto bíblico. A fim de resgatar a sua proposta original, Deus pratica screening, propondo um novo contrato de dois períodos, em que o homem deveria, no primeiro período, praticar os preceitos bíblicos, a fim de conquistar, no período seguinte, o prêmio por seu esforço. Este método é conhecido na literatura econômica como "estágio probatório". O Deus bíblico estaria, assim, gerando um equilíbrio separador, identificando entre as pessoas quais seriam o "trigo" e quais seriam o "joio".

As religiões de todos os tempos são construções que têm o objetivo de tentar superar a ignorância humana acerca de um suposto mundo espiritual. Assim, as mesmas seriam mecanismos criados para contornar um problema de assimetria informacional. As pessoas que adotam alguma prática religiosa assim o fazem, dentre outros motivos, porque se sentem inseguras em relação ao que poderia lhes acontecer após a sua morte, querendo obter, por meio do contrato religioso, um seguro em vida que lhes dê garantias de proteção quanto ao futuro após a morte.

Consideramos, neste trabalho, a existência de um mercado religioso de competição livre, imperfeita, entre as religiões, que competem pela adesão das pessoas aos seus dogmas, por meio do estabelecimento de um contrato religioso entre principais e agentes. No contrato religioso, os principais dão início à sequência de eventos, iniciando com a divulgação da sua doutrina religiosa aos agentes, em que estes optam por escolher ou não o contrato que lhes parece mais adequado ou que esteja de acordo com suas preferências ao longo do tempo.

De forma ampla e geral, pode-se concluir que o comportamento das pessoas que praticam algum credo ou religião está sob um "estágio probatório" por meio de screening.

Neste trabalho, desenvolvemos um modelo em que demonstramos a existência de um equilíbrio separador, em que os agentes são premiados ou não pelo principal. Esse prêmio está condicionado ao tempo dedicado à prática religiosa pelos agentes, critério empregado pelo principal para avaliar o comportamento dos mesmos, sob a ótica de um "jogo" seqüencial de informação incompleta através de screening.

Por fim, através dos dados da World Christian Encyclopedia, pode-se notar que oitenta e cinco por cento da população no mundo possui algum tipo de religião, sendo digno de nota ainda que uma parcela pequena da população professa mais de um credo. Pode-se notar que a grande maioria da dupla filiação está identificada entre os cristãos. Seria essa uma tentativa de minimizar o risco de não conseguir conquistar o "prêmio" no segundo período, por meio do "hedge" de um contrato religioso adicional?

\section{REFERÊNCIAS BIBLIOGRÁFICAS}

BANKS, J.S; SOBEL, J. "Equilibrium Selection in Signalling Games”. Econometrica, vol 55, pg.647-663, 1987.

Becking, B., Review by Biblical Games: Game Theory and the Hebrew Bible. The Online Journal for Philosophy of Religion Volume 3 (2003). Extraído em 25 de maio de 2004 de http://www.arsdisputandi.org/.

Bíblia Sagrada - Tradução da CNBB, Segunda edição Edições Loyola, São Paulo: 2002.

BRAMS, S. J., Biblical Games: Game Theory and the Hebrew Bible. Cambridge MA: 1982. 
BRAMS, S. J. Biblical Games: Game Theory and Hebrew Bible. Mit Press: 2003.

CHO, I. K.; KREPS, D. "Signalling Games and Stable Equilibria”. Quarterly Journal of Economics, vol 102, pg. 179-221, 1987.

DIAMOND, Peter A., National debt in a neoclassical growth model. American Economic Review 55 (Dezembro) p. $1126-$ 1150: 1965.

IANNACCONE, Laurence R. Introduction to the Economics of Religion. Journal of Economic Literature, 36(3), pp. 14651496.

HOBBES, Thomas. Leviatã. Editora Martin Claret, São Paulo , 2003.

LAZEAR, Edward P. "Personnel economics: past lessons and future directions". Journal of Labor Economics, v. 17, n. 2, p. 199-236, 1998.

MAS-COLELL, Andreu; et allii. Microeconomy Theory. Oxford University Press, 1995.

MOLHO, Ian. The Economic of Information. Blackwell Publishers, 1997.

ROMER, David. Advanced macroeconomics. McGraw-Hill: 1996.

SPENCE, Michael. “Job Market Signaling”. Quarterly Journal of Economics, vol 87, pgs. 355-374, 1973.

STADLER, Inês Macho; CASTRILLO, J. David Pérez. An Introduction to the Economics of Information. Oxford University Press, 1997.

WEBER, Max. A Ética Protestante e o Espírito do Capitalismo. Editora Martin Claret, São Paulo , 2001.

World Christian Database - Center for the Study of Global Christianity - Gordon-Conwell Theological Seminary. Extraído em outubro de 2006 de http://www.worldchristiandatabase.org/. 